\title{
Üniversite Öğrencilerinde Tip 2 DM Riski ve İlişkili Faktörler
}

\author{
Eylem Topbaş®
}

Amasya Üniversitesi Sağlık Bilimleri Fakültesi, Hemşirelik Böülümü, Amasya, Türkiye

Eylem Topbaş, Dr. Öğr. Üyesi

Illetişim:

Dr. Öğr. Üyesi Eylem Topbaş

Amasya Üniversitesi Sağlık Bilimleri Fakültesi, Hemşirelik Bölümü, Amasya, Türkiye Tel: +90358218 1767

E-Posta: eylem.topbas@gmail.com

Gönderilme Tarihi : 12 Nisan 2018

Revizyon Tarihi : 05 Ağustos 2018

Kabul Tarihi : : 02 Ekim 2018

\section{ÖZET}

Amaç: Sağlık Yüksekokulu öğrencilerinde Tip 2 diyabet riskinin ve bu riski etkileyen faktörlerin belirlenmesidir.

Yöntem: Tanımlayıcı kesitsel tipte olan çalışmanın evrenini diyabet tanısı olmayan Sağlık Yüksekokulu öğrencileri ( $n=406)$, örneklemini ise araştırmaya katılmaya istekli öğrenciler $(n=280)$ oluşturmaktadır. Veriler Mart-Nisan 2015 tarihleri arasında yüz yüze görüşme yöntemi ile araştırmacılar tarafından ilgili literatür taranarak oluşturulan "Kişisel Bilgi Formu" ve "Tip 2 Diyabet Risk Anketi" aracilığı ile elde edilmiştir. Veriler SPSS 20 paket programına aktarılarak, ortalama, yüzdelik hesaplama, ki kare testi, Kruskal Wallis-H Testi ile analiz edilmiştir.

Bulgular: Yaşları 21 $\pm 20,96$ olan öğrencilerin \%83,6'sı bayandır. Öğrencilerin \%3,2'sinde kalp hastalığı, \%1,4'ünde hiperlipidemi, \%0,4'ünde kanser olduğu, \%3,2'sinin psikiyatrik tedavi aldığı, \%15,7'sinin sigara içtiği, \%5'inin alkol kullandığı, \%5'inin doktoru tarafından önerilen özel bir diyet yaptığı, \%2,5'inin orta ve daha yüksek DM riskinin olduğu, \%27,1'inin hafif DM riskinin olduğu saptandı. Tip 2 DM riskini istatistiksel anlamlııkla etkileyen faktörler; doktorun özel bir diyet önermesi, sigara kullanımı, psikiyatrik tedavi almaları ve alkol kullanımıdır. Bu faktörlere evet yanıtı verenlerde DM görülme riskinin arttığı söylenebilir. Yaş, cinsiyet, öğrenim gördükleri sınıf, hiperlipidemi, kalp hastalığı, kanser geçirme durumlarının ise Tip 2 DM riskini etkilemediği belirlendi.

Sonuç: DM gelişimde etkili faktörler doktorun özel bir diyet önermesi, sigara kullanımı, psikiyatrik tedavi almaları ve alkol kullanmaları idi.

Anahtar sözcükler: Tip 2 diyabet, diyabet riski, FINDRISK, üniversite öğrencileri

\section{TYPE 2 DIABETES MELLITUS (DM) RISK IN UNIVERSITY STUDENTS AND RELATED FACTORS}

\section{ABSTRACT}

Aim: This study aims to identify the risk factors for Type 2 diabetes in students of school of health and related factors.

Method: The population of the descriptive cross-sectional study consists of healthy students studying in School of Health ( $n=406)$ and the sample which consists of students who volunteered to participate in the study $(n=280)$. The data were collected between March-April 2015by face to face meetings and by using "Personal Information Form" and "Type 2 Diabetes Risk Questionnaire" which is composed/written by researchers by/after reviewing the relevant literature. The data were transferred to the SPSS 20 package program and analysed by using mean, chisquare test, and Kruskal Wallis- $\mathrm{H}$ test.

Results: The age of the students was $21 \pm 20.96$ and $83.6 \%$ of them were female. It was detected that $3.2 \%$ of the students had cardiac disease, $1.4 \%$ had hyperlipidemia, $0.4 \%$ had cancer, $3.2 \%$ received psychiatric treatment, $15.7 \%$ smoke, $5 \%$ use alcohol, $5 \%$ followed a special diet suggested by their doctors, $2.5 \%$ had medium or highDM risk and $27.1 \%$ had low DM risk. The factors affecting the Type 2 DM risk with a statistical significance are; a special diet suggested by the doctor, smoking, receiving psychiatric treatment and using alcohol. In those who answered yes to these factors, It can be said that the risk of DM is increased. It was also determined that factors such as age, gender, grade, hyperlipidemia, cardiac disease and cancer did not affect the risk of Type 2 DM.

Conclusion: Factors affecting the development of DM Type 2 are: special diet suggested by the doctor, smoking, receiving psychiatric treatment and using alcohol.

Keywords: Type 2 diabetes, risk for diabetes, FIND RISK, university student 
D iyabet, insülin eksikliği ya da insülin etkisindek defektler nedeniyle organizmanın karbonhidrat, yağ ve proteinlerden yeterince yararlanamadığı, sürekli tıbbi bakım gerektiren, kronik bir metabolizma hastalığıdır. Tip 2 DM ortaya çıkmadan önce, bozulmuş glukoz toleransı (BGT)'nın olduğu prediyabet olarak adlandırılan bir dönemi vardır (1). İran'da yapılan bir çalışmada Prediyabet olan bireylerin (\%40,6) \%16,8'inde 5 yıl sonra diyabet geliştiği belirtilmektedir (2). Tüm dünyada olduğu gibi Türkiye'de de Tip II diyabet (DM) riski giderek artmaktadır. FDI 2017 raporunda Türkiye'de 20-79 yaş arasındaki bireylerde ulusal DM prevelansın \%12,54 olduğu belirtilmektedir. Dünya genelinde 20-79 yaşlarında diyabetli 415 milyon birey olduğu bu sayının 2040 yılında 642 milyona (belirsizlik aralığı: 521-829 milyon) ulaşacağı, diyabet kaynaklı 5 milyon ölüm olduğu, diyabetlilerin 4/3'ünün düşük ve orta gelirli ülkelerde yaşadığı, sağlık harcamalarının 673 milyar ABD doları olduğu belirtilmektedir (3). Ayrıca diyabet prevelansının 2040 yılında \%10,4'e çıkarak artmaya devam edeceği, diyabet kaynaklı ölümler ve diyabet nedeniyle sağlık harcamaları, önemli sosyal, finansal ve sağlık sistemine etkileri ile dünya genelinde artmaya devam edeceği bildirilmiştir (3). Hastalığın, akut komplikasyon riskini azaltmak ve uzun dönemde tedavisi pahalı ve kronik (retinal, renal, nöral, kardiyak ve vasküler) sekellerinden korunmak için sağlık çalışanları ve hastaların sürekli eğitimi şarttır (4).

Dünya genelinde DM ile mücadelede çeşitli stratejiler ve risk gruplarının belirlenmesine dair çalışmalar devam etmektedir. Bu çalışma genç yaş grubunda DM riskinin ve ilişkili faktörlerin belirlenmesi amacıyla yapılmıştır.

\section{Yöntem}

Tanımlayıcı kesitsel tipte olan çalışmanın evrenini MartNisan 2015 tarihleri arasında diyabet tanısı olmayan Sağlık Yüksekokulundaki öğrenciler $(n=406)$, örneklemini ise araştırmaya katılmaya istekli öğrenciler $(n=280)$ oluşturdu. Veriler yüz yüze görüşme yöntemi ile araştırmacı tarafından oluşturulan "Kişisel Bilgi Formu" ve "Tip 2 Diyabet Risk Anketi (FINDRISK)" aracılığı ile elde edildi.

\section{Veri toplama araçları}

Kişisel Bilgi Formu: Yaş, cinsiyet, sınıf ve DM risk oluşturacak hastalık bilgileri (hiperlipidemi yüksekliği, kalp hastalığı, inme geçirme durumu, kanser tedavisi görmesi, doktorun özel bir diyet önerip önermediği, sigara kullanıp kullanmadığı, psikiyatrik tedavi alıp almadığı, alkol kullanıp kullanmadığı) içeren toplam 11 soru yer almaktadır.
Tip 2 Diyabet Risk Anketi: Diyabet risk anketi (FINDRISK) Finlandiya Tip 2 Diyabetten Korunma Programı kapsamında, Fin Diyabet Birliği'nce geliştirilmiştir (5). Türkiye Endokrinoloji ve Metabolizma Derneği tarafından da önerilen FINDRISK anketi erken dönemde Tip 2 diyabet riskini belirlemek için kullanılmaktadır. Ankette toplam sekiz soru bulunmaktadır. Sorulara verilen yanıtlar 0 ile 4 arasında puanlanmaktadır. Anketten elde edilen toplam puan ile bireyin gelecek 10 yıl içinde diyabet olma riski belirlenir (6). Toplam puana göre risk durumu aşağıdaki tablo 1'debelirtildiği şekilde değerlendirilmektedir.

Bu çalışmada Risk anketinin sınıflamasında orta, yüksek ve çok yüksek risk gruplarındaki öğrenci sayısı az olduğu için DM risk sınıflandırması düşük, hafif ve orta-daha yüksek olarak üç grupta sınıflandırıldı

Tablo 1. Diyabet risk skoru ve önümüzdeki on ylllık süreçteki risk oranları

\section{DIYABET RISK SKORU}

\begin{tabular}{lcc}
\hline Toplam skor & Risk derecesi & 10 yıllık risk \\
\hline$<7$ & Düşük & $\% 1(1 / 100)$ \\
$7-11$ & Hafif & $\% 4(1 / 25)$ \\
$12-14$ & Orta & $\% 16(1 / 6)$ \\
$15-20$ & Yüksek & $\% 33(1 / 3)$ \\
$>20$ & Çok yüksek & $\% 50(1 / 2)$
\end{tabular}

\section{istatistiksel analiz}

Veriler IBM SPSS 20.0 (IBM Co., Armonk, NY, USA) paket programına aktarılarak analiz edilmiştir. Nominal değişkenler arasındaki ilişkiler incelenirken Ki-Kare analizi uygulanmış olup gözelerdeki beklenen değerlerin \%20'sinin 5 'den küçük olması durumunda Monte Carlo Simülasyonu yardımıyla Pearson Ki-Kare analizi uygulanmıştır. Sonuçlar yorumlanırken anlamlılık düzeyi 0,05 olarak alınmıştır.

\section{Etik yaklașım}

Insan Hakları Helsinki Deklarasyonu doğrultusunda çalışma tamamlandı. Araştırmanın etik izinleri Amasya Üniversitesi Rektörlüğü ve Sağlık Yüksekokulu Müdürlüğünden yazılı olarak alındı (Sayı:30640013-044265). Veri toplama formlarının doldurulmadan önce çalışmanın amacı katılımcılara açıklandı ve gönüllük esasına dayalı olarak sözel izinleri alındıktan sonra veriler toplandı.

\section{Bulgular}

Yaşları 21 20,96 olan öğrencilerin \%83,6'sı bayandır. Öğrencilerin \%3,2'sinde kalp hastalığı, \%1,4'ünde hiperlipidemi, \%0,4'ünde kanser olduğu, \%3,2'sinin psikiyatrik 
tedavi aldığı, \%15,7'sinin sigara içtiği, \%5'inin alkol kullandığı, \%5'inin doktoru tarafından önerilen özel bir diyeti olduğu saptandı. Öğrencilerin Tip 2 DM riskleri: \%2,5'inin orta ve daha yüksek, \%27,1'inin ise hafif idi (Tablo 2).

Tablo 2. Çalışmaya katılanların demografik özellikleri ifadesinde özelliklerinin dağlımı $(n=280)$

\begin{tabular}{|c|c|c|}
\hline Değişken & & $n(\%)$ \\
\hline \multirow[t]{2}{*}{ Cinsiyet } & Erkek & $46(\% 16,4)$ \\
\hline & Kadın & $234(\% 83,6)$ \\
\hline \multirow[t]{4}{*}{ Sinif } & 1.Sinıf & $54(\% 19,3)$ \\
\hline & 2.Sınıf & $62(\% 22,1)$ \\
\hline & 3.Sinif & $81(\% 28,9)$ \\
\hline & 4.Sınıf & $83(\% 29,6)$ \\
\hline \multirow{2}{*}{$\begin{array}{l}\text { Hiperlipidemi Kolestrol } \\
\text { Yüksekliğiniz Var Mı? }\end{array}$} & Evet & $4(\% 1,4)$ \\
\hline & Hayır & $276(\% 98,6)$ \\
\hline \multirow[t]{2}{*}{ Kalp Hastalığınız Var Mı? } & Evet & $9(\% 3,2)$ \\
\hline & Hayır & $271(\% 96,8)$ \\
\hline \multirow[t]{2}{*}{ İnme/Felç Geçirdiniz Mi? } & Evet & $0(\% 0,0)$ \\
\hline & Hayır & $280(\% 100,0)$ \\
\hline \multirow[t]{2}{*}{ Kanser Tedavisi Oldunuz Mu? } & Evet & $1(\% 0,4)$ \\
\hline & Hayır & $279(\% 99,6)$ \\
\hline \multirow[t]{2}{*}{ Doktorunuz Size Özel Diyet Önerdi Mi? } & Evet & $14(\% 5,0)$ \\
\hline & Hayır & $266(\% 95,0)$ \\
\hline \multirow[t]{2}{*}{ Sigara Kullanıyor Musunuz? } & Evet & $44(\% 15,7)$ \\
\hline & Hayır & $236(\% 84,3)$ \\
\hline \multirow[t]{2}{*}{ Psikiyatrik Tedavi Aldınız Mı? } & Evet & $9(\% 3,2)$ \\
\hline & Hayır & $271(\% 96,8)$ \\
\hline \multirow[t]{2}{*}{ Alkol Kullandınız Mı? } & Evet & $14(\% 5,0)$ \\
\hline & Hayır & $266(\% 95,0)$ \\
\hline \multirow[t]{3}{*}{ Tip-2 Diyabet Riski } & Düşük & $197(\% 70,4)$ \\
\hline & Hafif & $76(\% 27,1)$ \\
\hline & $\begin{array}{l}\text { Orta ve daha } \\
\text { yüksek }\end{array}$ & $7(\% 2,5)$ \\
\hline
\end{tabular}

Tip 2 DM riskini istatistiksel anlamlılıkla etkileyen faktörler; doktorun özel bir diyet önermesi, sigara kullanımı, psikiyatrik tedavi almaları ve alkol kullanımıdır $(p<0,05)$. Bu faktörlere evet yanıtı verenlerde DM görülme riskinin arttığı söylenebilir.

Yaş, cinsiyet, öğrenim gördükleri sınıf, hiperlipidemi, kalp hastalığı, kanser geçirme durumlarının ise Tip 2 DM riskini etkilemediği belirlendi $(p>0,05)$. Sigara kullananların Tip 2 DM riski; \%43,2'sinde hafif, \%2,5'inde orta ve yüksek olduğu, psikiyatrik tedavi alanların Tip 2 DM riskinin \%22.2'sinde hafif, \%22,2'sinde orta ve yüksek olduğu, alkol kullananların Tip 2 DM riskinin; \%64,3'ünde hafif olduğu, kendilerine doktor tarafından özel bir diyet önerilenlerin Tip 2 DM riskinin; \%21,4'ünde hafif, \%21,4'ünde ise orta ve yüksek olduğu saptandı. Doktoru tarafından kendisine özel bir diyet önerilenlerin \%21,4'ünde Tip 2 DM riski'inin orta ve daha yüksek idi (Tablo 3 ).

\section{Tartışma}

FINRISK risk anketine göre öğrencilerin \%70'inde 10 yıl içinde DM gelişme riskleri düşüktü ve öğrencilerin \%27,1'inin DM gelişme riski hafif düzey olarak saptandı. Öğrencilerin genç yaş grubunda olması DM riskinin düşük olmasında etkili olabilir. Her ne kadar risk düşük olsa da gençler arasında sedentar yaşam ve obezitenin son yıllarda artması nedeni ile DM açısından gençlerin yakın takip edilmesi gerekir. Literatürde FINRISK risk anketine göre hemşirelerin $\% 17,8$ 'si düşük, $\% 16,9$ 'u hafif, $\% 19^{\prime}$ u orta, $\% 39,9$ 'u yüksek riks grubunda olduğu (7), öğrencilerin \%67,1'inde DM riskinin düşük (8) olduğu, başka bir çalışmada öğrencilerin $\% 15,2$ 'sinde riskin orta, \%1,8'inde düşük olduğu, yüksek risk grubundaki öğrencilerin \%29'unun ise kan glikoz düzeyi ölçümlerine göre DM tanısı aldıkları belirtilmektedir (9). Üniversiteli gençlerde Tip II DM risk prevelansının artması genç popülasyonda bu konuda eğitime ihtiyaç olduğunu göstermektedir (10). Çalışmamızda doktor tarafından özel bir diyet önerilmeyen öğrencilerin \%71,1'inde DM gelişme riski düşük bulundu. Beslenme alışkanlıklarının düzenlenmesi ve sağlıklı beslenme diyabetin değiştirilebilir risk faktörleri arasında yer almaktadır. Sağlıklı beslenme alışkanlıkları kazanarak diyabet gelişim riskini düşürebilir, diyabetin gelişmesini geciktirebilir ya da önleyebiliriz (7). Sedanter yaşam ve obezite üniversite gençlerinde Tip II DM gelişimine neden olmaktadır (11). Hindistanda dünya nüfusunun altıda birinin yaşadığı ve DM görülme sıklığının fazla olduğu, adölesanlarda Tip 2 DM riskini ve obeziteyi azaltmak için dengeli bir diyet ve fiziksel aktiviteyi içeren sağlıklı yaşam tarzı hakkında bilginin, eğitimin ve iletişimin üzerinde durulması gerektiğine dikkat çekilmektedir (12). Tıp öğrencileri ile Hint Diyabet risk skoru kullanılarak yapılan bir çalışmada öğrencilerin \%50'sinde Tip II DM gelişme riski bildirilmiştir (13). Yine Hint Diyabet Risk Skoru ve Amerikan Diyabet Derneği risk skoruna sonuçlarına göre üniversite öğrencilerinde Tip II DM gelişme riski orta düzeyde olduğu ve riskin obezite ile birlikte arttığı belirtilmektedir (14).

Bu çalışmada sigara ile DM riski arasında istatistiksel açıdan anlamlı ilişki elde edildi. Sigara içmek diyabet geliştirme riskini artırır $(15,16,17)$ ve diyabetin mikro ve makrovasküler komplikasyonlarını şiddetlendirir. Sigara içmek insülin direnci, inflamasyon ve dislipidemi ile ilişkilidir (18). 
Tablo 3. Tip -2 diyabet risk anketi sonuçlarının demografik özellikler ile ilişkilerine ilişkin Ki-Kare analizi sonuçları $(n=280)$

Tip-2 Diyabet Riski

\begin{tabular}{|c|c|c|c|c|c|c|c|}
\hline & & Düşük & Hafif & Orta ve daha yüksek & Toplam & \multicolumn{2}{|c|}{ Ki-Kare Analizi } \\
\hline & & $n(\%)$ & $n(\%)$ & $n(\%)$ & $n \%$ & Ki-Kare & $p$ \\
\hline \multirow[t]{2}{*}{ Cinsiyet } & Erkek & $32(\% 69,6)$ & $14(\% 30,4)$ & $0(\% 0,0)$ & $46(\% 100,0)$ & \multirow{2}{*}{1,601} & \multirow{2}{*}{0,449} \\
\hline & Kadın & $165(\% 70,5)$ & $62(\% 26,5)$ & $7(\% 53,0)$ & $234(100,0)$ & & \\
\hline \multirow[t]{4}{*}{ Sinif } & 1.Sinif & $43(\% 79,6)$ & $10(\% 18,5)$ & $1(\% 1,9)$ & $54(\% 100,0)$ & \multirow{4}{*}{ * } & \multirow{4}{*}{0,245} \\
\hline & 2.Sinif & $45(\% 72,6)$ & $14(\% 22,6)$ & $3(\% 4,8)$ & $62(\% 100,0)$ & & \\
\hline & 3.Sinif & $57(\% 70,4)$ & $22(\% 27,2)$ & $2(\% 2,5)$ & $81(\% 100,0)$ & & \\
\hline & 4.Sinif & $52(\% 62,7)$ & $30(\% 36,1)$ & $1(\% 1,2)$ & $83(\% 100,0)$ & & \\
\hline \multirow[t]{2}{*}{ Hiperlipidemi Kolestrol Yüksekliğiniz Var mı? } & Evet & $1(\% 25,0)$ & $3(\% 75,0)$ & $0(\% 0,0)$ & $4(\% 100,0)$ & \multirow{2}{*}{ * } & \multirow{2}{*}{0,157} \\
\hline & Hayır & $196(\% 71,0)$ & $73(\% 26,4)$ & $7(\% 2,5)$ & $276(\% 100,0)$ & & \\
\hline \multirow[t]{2}{*}{ Kalp Hastalığınız Var mı? } & Evet & $8(\% 88,9)$ & $0(\% 0,0)$ & $1(\% 11,1)$ & $9(\% 100,0)$ & \multirow{2}{*}{ * } & \multirow{2}{*}{0,051} \\
\hline & Hayır & $189(\% 69,7)$ & $76(\% 28,0)$ & $6(\% 2,2)$ & $271(\% 100,0)$ & & \\
\hline \multirow[t]{2}{*}{ Kanser Tedavisi Oldunuz mu? } & Evet & $1(\% 100,0)$ & $0(\% 0,0)$ & $0(\% 0,0)$ & $1(\% 100,0)$ & \multirow{2}{*}{ * } & \multirow{2}{*}{1,000} \\
\hline & Hayır & $196(\% 70,3)$ & $76(\% 27,2)$ & $7(\% 2,5)$ & $279(\% 100,0)$ & & \\
\hline \multirow[t]{2}{*}{ Doktorunuz Size Özel Diyet Önerdi mi? } & Evet & $8(\% 57,1)$ & $3(\% 21,4)$ & $3(\% 21,4)$ & $14(\% 100,0)$ & \multirow{2}{*}{ * } & \multirow{2}{*}{0,003} \\
\hline & Hayır & $189(\% 71,1)$ & $73(\% 27,4)$ & $4(\% 1,5)$ & $266(\% 100,0)$ & & \\
\hline \multirow[t]{2}{*}{ Sigara Kullanıyor musunuz? } & Evet & $24(\% 54,5)$ & $19(\% 43,2)$ & $1(\% 2,3)$ & $44(\% 100,0)$ & \multirow{2}{*}{6,813} & \multirow{2}{*}{0,033} \\
\hline & Hayır & $173(\% 73,3)$ & $57(\% 24,2)$ & $6(\% 2,5)$ & $236(\% 100,0)$ & & \\
\hline \multirow[t]{2}{*}{ Psikiyatrik Tedavi Aldınız mı? } & Evet & $5(\% 55,6)$ & $2(\% 22,2)$ & $2(\% 22,2)$ & $9(\% 100,0)$ & \multirow{2}{*}{ * } & \multirow{2}{*}{0,017} \\
\hline & Hayır & $192(\% 70,8)$ & $74(\% 27,3)$ & $5(\% 1,8)$ & $271(\% 100,0)$ & & \\
\hline \multirow[t]{3}{*}{ Alkol Kullandınız mı? } & Evet & $5(\% 35,7)$ & $9(\% 64,3)$ & $0(\% 0,0)$ & $14(\% 100,0)$ & \multirow[t]{3}{*}{ * } & \multirow{3}{*}{0,013} \\
\hline & Hayır & $192(\% 72,2)$ & $67(\% 25,2)$ & $7(\% 2,6)$ & $266(\% 100,0)$ & & \\
\hline & Toplam & $197(\% 70,4)$ & $76(\% 27,1)$ & $7(\% 2,5)$ & $280(\% 100,0)$ & & \\
\hline
\end{tabular}

* Gözelerdeki beklenen değerlerin \%20'den fazlasının 5'den küçük olması nedeniyle Monte Carlo Simülasyonu yardımıyla Pearson Ki-Kare Analizi uygulanmıştır.

Bu çalışmada psikiyatrik tedavi alma ile diyabet arasında istatistiksel açıdan anlamlı ilişki elde edildi. Literatürde de Tip 1 ve Tip 2 DM'nin anksiyete, depresyon ve yeme bozukluğu gelişimi ile ilişkili olduğu belirtilmektedir (19). Diyabette tedavi maliyetleri ve komplikasyonların ortaya çıkmasının anksiyeteyi arttırdığı bildirilmektedir (19). Bu nedenle DM riski altındaki bireylerde rutin ruh sağlığı açısından da kontrollerin yapılması tedavi sürecini olumlu etkileyecektir.

Çalışmamızda alkol tüketimi ile DM riski arasında istatistiksel açıdan anlamlı ilişki bulundu. Alkol kullanmayan bireylerin DM riski düşüktü. Yüksek düzeyde alkol tüketimi Tip 2 DM riskini arttırdığı belirtilmektedir (20). Sosyoekonomik gelişmelere eşlik eden yaşam tarzı, obezite, sigara, alkol ve erkek olmak Tip II DM gelişimi için risk faktörüdür (21). Hızlı sosyoekonomik büyüme sağlıksız beslenme alışkanlıkları Tip II DM gelişimi ile ilişkilendirilmektedir (22). Fiziksel inaktivite, modern yaşam, şeker ve yağ alımının arttırıması da modern yaşamda Tip II DM gelişiminde risk faktörü olarak karşımıza çıkmaktadır (23). Gelişmekte ve kentleşmekte olan ülkelerde DM'yi önlemeye yönelik sağlık politikaları belirlenirken bu faktörler göz önünde bulundurulmalıdır. Ayrıca genç nüfusta Tip II DM gelişme riskini azaltmak için doğru kanallarla eğitim verilmelidir. Gençlerin sıklıkla kullandığı sosyal medya, akıllı telefon, tablet, video paylaşım siteleri farkındalık eğitimleri ve DM ile ilgili spot mesaj vermek için kullanılabilir (24). Ayrıca Genç erişkinlerde kişilik özellikleri, sağlıkla ilgili davranışlar ve vücut kitle indeksinin Tip II DM risk algısı ile ilişkili olduğundan, DM riskini azaltmak için kişilik özelliklerine de dikkat etmek gerekmekte ve çok boyutlu bir mücadele stratejisi benimsemek gerekmektedir (25).

\section{Sonuç}

Tip 2 DM gelişiminde risk faktörü olan hiperlipidemi, kalp hastalığı, inme, kanser geçirme durumunun örneklem grubunda düşük olmasına rağmen önümüzdeki 10 yıllık süreçte Tip 2 DM gelişme riski hafif düzeyde bulundu. 
Çalışmamızda DM riski ile sigara, alkol kullanımı, doktorun özel diyet önerme durumu ve psikiyatrik tedavi alma durumlarının etkilediği bulundu. Bu nedenle gençlerde alkol ve sigara tüketiminin azaltılmasına yönelik stratejilerin geliştirilmesi, psikiyatrik bozuklukların zamanında tedavi edilmesi ve düzenli dengeli beslenme alışkanlıklarının geliştirilmesi için öğrencilere destek olunması gerekmektedir. Ayrıca gençlere DM gelişimine neden olan faktörler,

\section{Kaynaklar}

1. Özbal FS, Tekeli S, Akıncı E, Dedeoğlu H, Metin V, Yılmaz M, et al. Tip 2 diyabet; tehlikenin farkında mısınız? Genel Tıp Derg 2016;26 (Ek 1):1-6.

2. Latifi SM, Karandish M, Shahbazian H, Pasand HL. Incidence of Prediabetes and Type 2 Diabetes among People Aged over 20 Years in Ahvaz: A 5-Year Perspective Study (2009-2014), Journal of Diabetes Research 2016:1-6.

3. Ogurtsova $K$, da Rocha Fernandes JD, Huang $Y$, Linnenkamp U, Guariguata L, Cho NH, et al. IDF Diabetes Atlas: Global estimates for the prevalence of diabetes for 2015 and 2040. Diabetes Research and Clinical Practice 2017;128:40-50. [CrossRef]

4. Temd Diabetes Mellitus ve Komplikasyonlarının Tanı, Tedavi ve İzlem Kılavuzu-2017. http://www.turkendokrin.org/files/DIYABET2017_ web.pdf.

5. Finnish Diabetes Association, Programme for the Prevention of Type 2 Diabetes in Finland 2003 2010. https://www.diabetes.fi/ files/1108/Programme_for_the_Prevention_of_Type_2Diabetes_ in_Finland_2003-2010.pdf

6. Türkiye Endokrin ve Metabolizma Derneği (TEMD) Diabetes Mellitus ve Komplikasyonlarının Tanı, Tedavive İzlem Kılavuzu 2015. http:// www.turkendokrin.org/files/15055_DIYABET_web(1).pdf.

7. Yurtsever S, Yürügen $B$, Saraç T, Şit D. Diyabet Riski Düşük ve Yüksek Olan Hemşirelerde İnsülin Direnci Varlığının Araştırılması, Diyabet, Obezite ve Hipertansiyonda Hemşirelik Forumu Derg 2014;6:53-62.

8. Gezer C, Hemşirelik Bölümü Öğrencilerinde Bel/Boy Oranı ve Tip 2 Diyabet Riski Ilişkisinin Değerlendirilmesi. J Food and Health Science 2017;3:141-9. [CrossRef]

9. Al-Shudifat AE, Al-Shdaifat A. Al-Abdouh AA, Aburoman Ml, Otoum SM, Sweedan AG, Diabetes Risk Score in a Young Student Population in Jordan: A Cross-Sectional Study. J Diabetes Res 2017;1-5. [CrossRef]

10. Sealey-Potts C, Reyes-Velazquez W. Perceived and Actual Risks of College Students for Developing Type 2 Diabetes. Austin J Nutr Metab 2014;1: 1-5.

11. Lima ACS, Araújo MFM, de Freitas RWJF, Zanetti ML, de Almeida PC, Damasceno MMC. Risk factors for Type 2 Diabetes Mellitus in College Students: Association with Sociodemographic Variables. Rev. LatinoAm. Enfermagem 2014;22:484-90. [CrossRef]

12. Achuth KS, Mangala S, Pradeep C, Mini J, Subrahmanyam G. Risk of Type 2 Diabetes Mellitus in Adolescents in a Medical College in Bangalore, India. Int J Scientific Study 2015;3:86-9. [CrossRef] komplikasyonları, hastalık yönetimi gerek derslerde gerekse konferans, seminer ve hasta başı uygulamaları sırasında anlatılması ve hatırlatılması önerilmektedir.

\section{Teşekkür}

Çalışmada verilerin toplanmasında desteği olan öğrencilerimiz Elif Başyaman, Aycan Gülmez, Gülçin Bat ve Sedanur Tüfekçi'ye teşekkür ederim.

13. Aswa J, Shankar V, Garg S, Kutty K. Risk of type 2 Diabetes Mellitus in Medical Students. Int J Comprehensive Medical Physiology And Res 2014;1:6-9.

14. Garg S, Maharana SP. Study on Prediction of Type 2 Diabetes Mellitus in Undergraduate MBBS Students: A Cross-section Study in a Tertiary Health Center, Kolkata. Int J Res Med Sci 2018;6:184-90. [CrossRef]

15. Ko SH, Kim SR, Kim DJ, Oh SJ, Lee HJ, Shim KH, et al. Committee of Clinical Practice Guidelines, Korean Diabetes Association. Diabetes Metab J. 2011; 35:431-6. [CrossRef]

16. Cho NH, Chan JC, Jang HC, Lim S, Kim HL, Choi SH. Cigarette smoking is an independent risk factor for type 2 diabetes: a fouryear community-based prospective study. Clin Endocrinol (Oxf). 2009; 71:679-85. [CrossRef]

17. Jee SH, Foong AW, Hur NW, Samet JM. Smoking and risk for diabetes incidence and mortality in Korean men and women. Diabetes Care 2010;33:2567-72. [CrossRef]

18. Chang SA. Smoking and Type 2 Diabetes Mellitus. Diabetes Metab J 2012; 36: 399-403. [CrossRef]

19. Ducat L, Philipson LH, Anderson BJ. The Mental Health Comorbidities of Diabetes. JAMA. 2014; 312: 691-2. [CrossRef]

20. Carlsson S, Hammar N, Grill V, Kaprio J. Alcohol consumption and the incidence of type 2 diabetes: a 20-year follow-up of the Finnish twin cohort study. Diabetes Care 2003;26:2785-90. [CrossRef]

21. Papier K, Jordan S, D'Este C, Bain C, Peungson J, Banwell C, et al. Incidence And Risk Factors For Type 2 Diabetes Mellitus in Transitional Thailand: Results from the Thai Cohort Study. BMJ Open 2016;6:e014102. [CrossRef]

22. Fareed M, Salam N, Khoja AT, Mahmoud MA, Ahamed M. Life Style Related Risk Factors of Type 2 Diabetes Mellitus and Its Increased Prevalence in Saudi Arabia: A Brief Review. Int J Med Res Health Sci 2017;6: 125-32.

23. Chirkov VT, Balde NM, Chirkov V. Lifestyle Change and Type 2 Diabetes Mellitus Risk Factors Among Students of the Medical Faculty of Conakry (Guinea). Phys Med Rehabil Res 2017; 2;1-5. [CrossRef]

24. Reyes-Velázquez W, Hoffman EW. Toward Reducing the Diabetes Pandemic: College Students' Perspectives of Type 2 Diabetes. Diabetes Spectrum 2011;24:161-8. [CrossRef]

25. Skøt L, Nielsen JB, Leppin A. Who Perceives a Higher Personal Risk of Developing Type 2 Diabetes? A Crosssectional Study on Associations Between Personality Traits, Health-Related Behaviours and Perceptions of Susceptibility Among University Students in Denmark. BMC Public Health 2018;18:972. [CrossRef] 